Research Article

\title{
To evaluate the creatinine clearance and compare nephrotoxic potential of amikacin and gentamicin, in post-operative patients with normal baseline renal function
}

\author{
Subarna Bajracharya ${ }^{1}$, Krishna Pandey ${ }^{2}$, Ataul Haque ${ }^{1}$
}

\begin{abstract}
${ }^{1}$ Department of Pharmacology, Teerthanker Mahaveer Medical College, Uttar Pradesh Province, India

${ }^{2}$ Department of Pharmacology, Mayo Institute of Medical Sciences, Uttar Pradesh Province, India
\end{abstract}

Received: 24 June 2016 Accepted: 05 August 2016

*Correspondence to: Dr. Krishna Pandey, Email: krishnapandey0507@ hotmail.com

Copyright: () the author(s), publisher and licensee Medip Academy. This is an openaccess article distributed under the terms of the Creative Commons Attribution NonCommercial License, which permits unrestricted noncommercial use, distribution, and reproduction in any medium, provided the original work is properly cited.

\begin{abstract}
Background: The majority of infections on any surgical ward are usually due to one or more of the gram-negative bacilli. Among the different groups of antimicrobials that have been used to treat these infections, Aminoglycoside antibiotics such as Amikacin and Gentamicin are the most commonly used.

Methods: The study is 1 year, non-interventional, prospective study of patients administered either Amikacin or Gentamicin following surgery carried out in surgery ward in co-ordination with department of Pharmacology, Teerthanker Mahaveer Medical College and Research Centre Moradabad.

Results: The mean difference in final and initial serum creatinine values were observed to be 0.32 and 0.52 with a standard deviation of 0.228 and 0.387 in $\mathrm{AM}$ and GM group respectively. This difference was statistically significant with $\mathrm{p}$ value of 0.007 . The mean difference in final and initial creatinine clearance values were observed to be 18.82 and 24.76 with a standard deviation of 10.14 and 11.93 in AM and GM group respectively. This difference was also statistically significant with p-value of 0.013 . Nephrotoxicity occurred in 9 out of 50 patients $(18 \%)$ in AM group out of which $12 \%$ were male and $6 \%$ were female whereas in case of GM group nephrotoxicity occurred in 16 out of 50 patients (32\%) in which $26 \%$ were male and $6 \%$ were female.

Conclusions: From this study we can conclude that Gentamicin is more nephrotoxic and causes greater fall in creatinine clearance although the dose of Gentamicin administered is much lower compared to Amikacin.
\end{abstract}

Keywords: Amikacin, Gentamicin, Nephrotoxicity, Creatinine

\section{INTRODUCTION}

In surgical ward, majority of infections are usually due to one or more of the gram-negative bacilli. Aminoglycosides have proven to be the most effective among different groups of antimicrobials that have been used. ${ }^{1}$

After their introduction into therapeutic practice in 1944, Aminoglycoside antibiotics such as Amikacin and Gentamicin are the most commonly used antibiotics worldwide for the treatment of gram-negative bacterial infections. However, serious complications like nephrotoxicity and ototoxicity are dose-limiting factors in the use of aminoglycosides. ${ }^{2}$

In $10-25 \%$ of therapeutic courses, aminoglycoside antibiotics induce a dose-dependent nephrotoxicity even despite rigorous monitoring of serum drug concentration and adequate fluid volume control. ${ }^{3,4}$

Neuromuscular blocks are rare, ototoxicity ranges from 0 to $62 \%$ (cochlear) and 0 to $19 \%$ (vestibular) and nephrotoxicity varies from 0 to $50 \% .^{5}$ 
For dosing and monitoring drugs excreted by the kidneys, such as the Aminoglycoside antibiotics, estimation of creatinine clearance is a common method. Serum creatinine concentration (S.Cr) is among the most reliable markers of renal function, as creatinine is produced at a constant rate, almost exclusively cleared through glomerular filtration, and rapidly and inexpensively measured. A 24-hour urine collection provides the most accurate $\mathrm{Cr} . \mathrm{Cl}$ when properly performed; however, this method is labour-intensive and time-consuming, making it impractical for use in immediate medication dosing. Consequently, several nomograms and equations have been developed to estimate $\mathrm{Cr} . \mathrm{Cl}$ from S.Cr, most of which account for age, weight, sex, and S.Cr. ${ }^{6}$ Of these methods, the equation developed by Cockcroft and Gault was one of the most universally used. ${ }^{7}$

The objective of this study was to define the demographic characteristics of aminoglycoside treated patients. And to compare the nephrotoxic potential of Amikacin and Gentamicin. And to evaluate the creatinine clearance in both Amikacin and Gentamicin treated post-operative patients. To find out the less nephrotoxic aminoglycoside suitable for administration to post-operative patient.

\section{METHODS}

The design of this study was 1 year, non-interventional, prospective study of patients administered either AM or GM following surgery carried out in surgery ward in coordination with department of pharmacology, TMMC and RC, Moradabad.

The population of this study was patients receiving aminoglycoside treatment, GM or AM in surgery ward with basal S.Cr level. A simple random sample of 100 patients was taken from surgery ward.

\section{Inclusion criteria}

- Patients undergoing abdominal and other surgery who are at the high risk of developing post-surgical infections

- Patient with initial serum creatinine level $\leq 1.2 \mathrm{mg} / \mathrm{dl}$

- Administration of either GM or AM for not less than five days.

\section{Exclusion criteria}

- Patient having acute or chronic renal disease with relatively less renal functions and who are undergoing haemodialysis

- Pregnant and lactating women

- History of either AM or GM administration in previous month

- Patient who are hypersensitive to any of the aminoglycosides.

\section{Techniques of data collection}

Primary data collection through interaction with the admitted patient and through records maintained at surgery ward at nurse station.

\section{Duration of data collection}

The duration of this study was 1 year, and ethical approval was taken from the university ethical committee, Informed consent form was taken from the patient, confidentiality of information and privacy were assured.

\section{Statistical analysis}

Continuous variables were described using mean \pm standard deviation (SD). The proportion of patients developing nephrotoxicity in the study population was expressed as frequency and percentage. The association between nephrotoxicity and the variables of interest was evaluated using Pearson Chi-square or Fishers' exact test for categorical variables and the independent student's $t$ test for continuous variables. Differences in serum creatinine and creatinine clearance level between consecutive days were tested using paired - samples $\mathrm{T}$ test. Data analysis and graphics were carried out using SPSS 21 and MS excel 2008.

\section{RESULTS}

\section{Demographic status of patients}

A total of 100 patients were studied during the period of 1 year. The patients were randomly divided into two groups i.e. Amikacin (AM) group and Gentamicin (GM) group with equal number of population.

Table 1: Demographic status of patients.

\begin{tabular}{|lllll|}
\hline $\begin{array}{l}\text { Age- } \\
\text { range }\end{array}$ & $\begin{array}{l}\text { Amikacin group } \\
\text { No of } \\
\text { patient }\end{array}$ & Percent & $\begin{array}{l}\text { Gentamicin group } \\
\text { No of } \\
\text { patient }\end{array}$ & Percent \\
\hline$<20$ & 4 & 8.0 & 4 & 8.0 \\
\hline $21-30$ & 7 & 14.0 & 8 & 16.0 \\
\hline $31-40$ & 6 & 12.0 & 8 & 16.0 \\
\hline $41-50$ & 8 & 16.0 & 5 & 10.0 \\
\hline $51-60$ & 7 & 14.0 & 6 & 12.0 \\
\hline $61-70$ & 11 & 22.0 & 13 & 26.0 \\
\hline $71-80$ & 7 & 14.0 & 6 & 12.0 \\
\hline Total & $\mathbf{5 0}$ & $\mathbf{1 0 0 . 0}$ & $\mathbf{5 0}$ & $\mathbf{1 0 0 . 0}$ \\
\hline
\end{tabular}

The study revealed that, most of the patient in Amikacin group belongs to age group 61-70 year 22\% $(\mathrm{n}=11)$, followed by age group 41-50 year was $16 \%(n=8)$, Similarly, in Gentamicin group highest percentage of patient belong to age group 61-70 year was $26 \%(n=13)$, followed by age group 31-40 and 21-30 with equal percentage of $16 \%(n=8)$. The mean age in AM and GM 
group were 49.72 and 48.58 with a standard deviation of 18.78 and 19.19 respectively $(p$-value $=0.725)($ Table 1$)$.

In gender distribution there were $52 \%(\mathrm{n}=26)$ males and $24 \%(\mathrm{n}=48)$ females in AM group. In GM group, the male and female population were observed to be equal i.e. $50 \%(\mathrm{n}=25)$. The mean weight in $\mathrm{kg}$ were 55.48 and 54.66 with standard deviation of 10.44 and 9.18 in AM and GM group respectively. The mean height in Meters were 1.61 and 1.6 with S.D of 0.072 and 0.081 in AM and GM group respectively.

The post-operative patients in AM group were observed to be highest with a history urethral sphincter $12 \%(\mathrm{n}=$ $6)$, perforation $12 \%(n=6)$ followed by liver abscess $10 \%$ $(\mathrm{n}=5)$, renal calculus $8 \%(\mathrm{n}=8)$, cholelithiasis $8 \%(\mathrm{n}=$ 4), ovarian cyst $8 \%(n=4)$, intestinal obstruction $8 \%(n=$ 4) followed by prosectomy $6 \%(\mathrm{n}=3)$, appendicitis $4 \%$ $(n=2)$, hernia $4 \%(n=2)$, hydrocele $4 \%(n=2)$, sinus $4 \%$ $(n=2)$, lipoma back $4 \%(n=2)$, swelling in thigh $2 \%$ $(n=1)$ and others $6 \%(n=3)$. The post-operative patients in $\mathrm{Gm}$ group were observed to be highest with history Renal calculus $14 \%(\mathrm{n}=7)$, intestinal obstruction $10 \%$ (n $=5)$, cholelithiasis $10 \%(\mathrm{n}=5)$ followed by lipoma back $8 \%(\mathrm{n}=4)$, liver abscess $8 \%(\mathrm{n}=4)$, ovarian cyst $6 \%(\mathrm{n}=$ $3)$, penile growth $6 \%(n=3)$, appendicitis $6 \%(n=3)$, perforation $6 \%(n=3)$, prosectomy $6 \%(n=3)$ followed by sinus $4 \%(n=2)$, hydrocele $4 \%(n=2)$, hernia $4 \%(n=2)$ followed by swelling in thigh $2 \%(\mathrm{n}=1)$, urethral sphincter 2\% $(n=1)$ and others $4 \%(n=2)$ (Figure 1$)$.

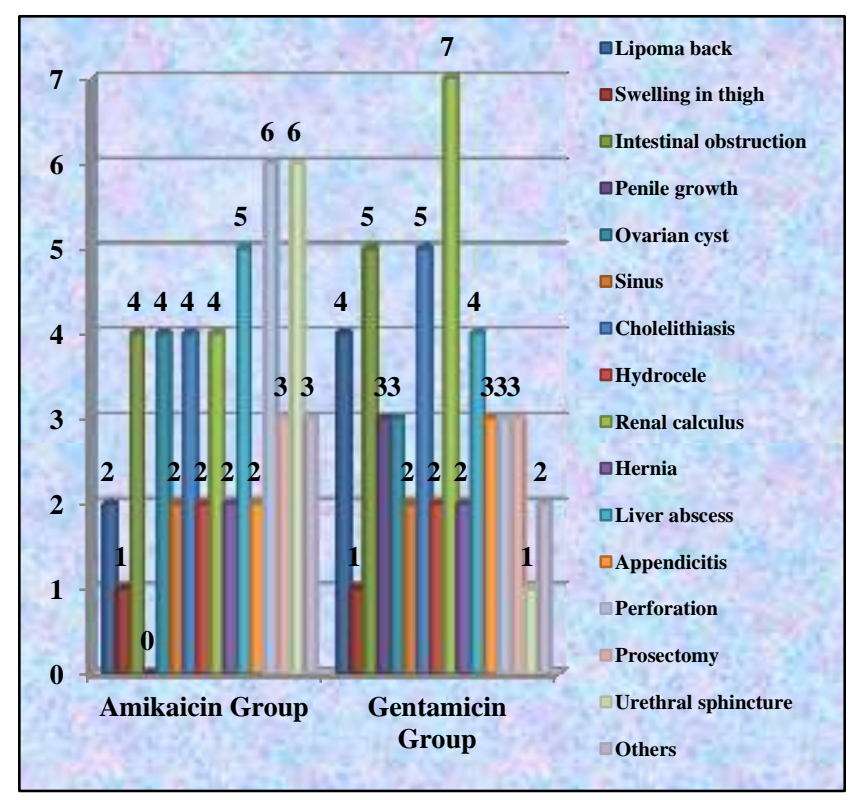

Figure 1: Demographic distribution of patient history of patient.

\section{Variables before surgery}

The initial Serum Creatinine value before undergoing surgery were $0.87 \mathrm{mg} / \mathrm{dL}$ and $0.86 \mathrm{mg} / \mathrm{dL}$ with a standard deviation of 0.172 and 0.184 in $\mathrm{AM}$ and GM group respectively. Considering gender, the mean S.Cr was $0.81 \mathrm{mg} / \mathrm{dl}$ and $0.93 \mathrm{mg} / \mathrm{dl}$ in female and male respectively in AM group. In GM group the mean S.Cr values were $0.82 \mathrm{mg} / \mathrm{dl}$ and $0.93 \mathrm{mg} / \mathrm{dl}$ in female and male respectively. There was no significant difference in initial S.Cr levels (Table 2 and Figure 2).

Table 2: general overview of demography and overall diagnosis.

\begin{tabular}{|llll|}
\hline Variable & AM group & GM group & P-value \\
\hline Age & $49.72 \pm 18.78$ & $48.58 \pm 19.19$ & 0.725 \\
\hline $\begin{array}{l}\text { Height } \\
\text { (in metre) }\end{array}$ & $1.61 \pm 0.072$ & $1.6 \pm 0.081$ & 0.48 \\
\hline $\begin{array}{l}\text { Weight } \\
\text { (in kg) }\end{array}$ & $55.48 \pm 10.44$ & $54.66 \pm 9.18$ & 0.69 \\
\hline $\begin{array}{l}\text { Dose } \\
\text { (per kg/d) }\end{array}$ & 14.4 & 2.5 & 0.00 \\
\hline $\begin{array}{l}\text { Duration of } \\
\text { treatment }\end{array}$ & 7.6 & 7.71 & 0.61 \\
\hline Initial S.Cr & $0.87 \pm 0.17$ & $0 \pm 0.18$ & 0.964 \\
\hline $\begin{array}{l}\text { Initial } \\
\text { Cr.Cl }\end{array}$ & $75.36 \pm 27.6$ & $76.97 \pm 28.76$ & 0.971 \\
\hline Final S.Cr & $1.195 \pm 0.3$ & $1.4 \pm 0.52$ & 0.046 \\
\hline Final Cr.Cl & $57.97 \pm 23.78$ & $52.21 \pm 25.18$ & 0.284 \\
\hline $\begin{array}{l}\text { Difference } \\
\text { in S.Cr }\end{array}$ & $0.32 \pm 0.228$ & $0.52 \pm 0.387$ & 0.007 \\
\hline $\begin{array}{l}\text { Difference } \\
\text { in Cr.Cl }\end{array}$ & $18.82 \pm 10.14$ & $24.76 \pm 11.93$ & 0.013 \\
\hline $\begin{array}{l}\text { Nephrotoxi } \\
\text { city }\end{array}$ & $9(18 \%)$ & $16(36 \%)$ & - \\
\hline
\end{tabular}

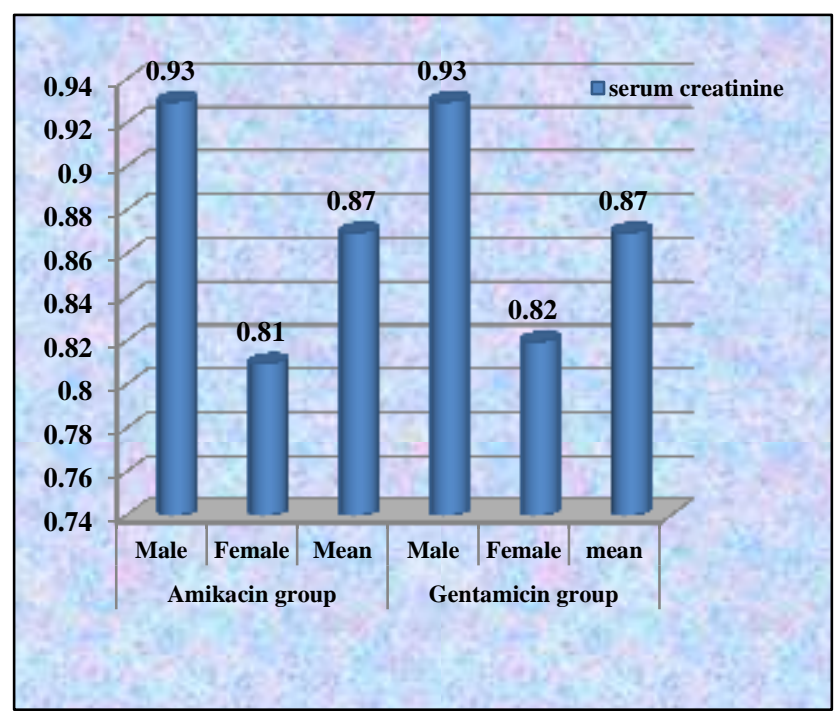

Figure 2: Serum creatinine before surgery.

The mean creatinine clearance value calculated by Cockcroft and Gault method were $76.74 \mathrm{~mL} / \mathrm{min}$ and $76.74 \mathrm{~mL} / \mathrm{min}$ with S.D of 27.61 and 28.76 in $\mathrm{AM}$ and GM group respectively. Considering the gender, $\mathrm{Cr} . \mathrm{Cl}$ is $74.10 \mathrm{~mL} / \mathrm{min}$ for female and $79.62 \mathrm{~mL} / \mathrm{min}$ for male in AM group and in GM group $73.95 \mathrm{~mL} / \mathrm{min}$ and 79.99 
$\mathrm{mL} / \mathrm{min}$ in female and male respectively. There was no significant difference in initial $\mathrm{Cr} . \mathrm{Cl}$ values among two groups (Table 2 and Figure 3).

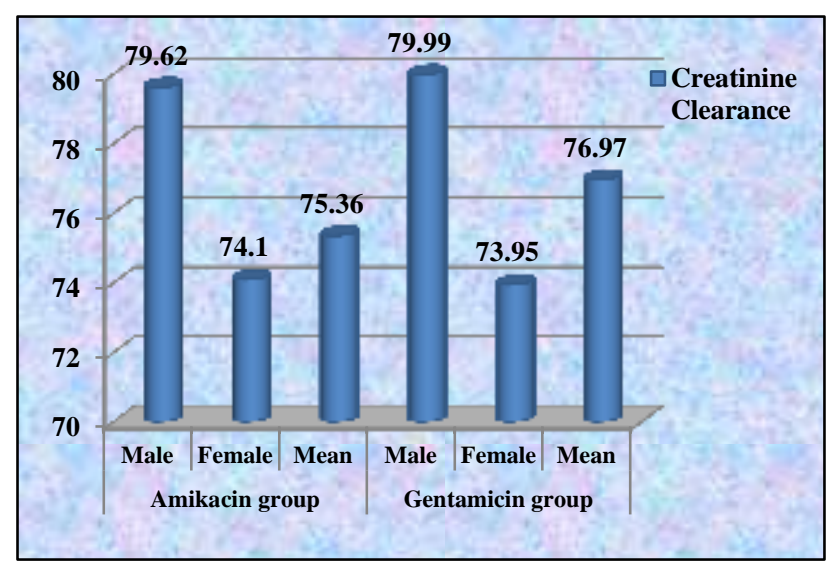

Figure 3: Creatinine clearance before surgery.

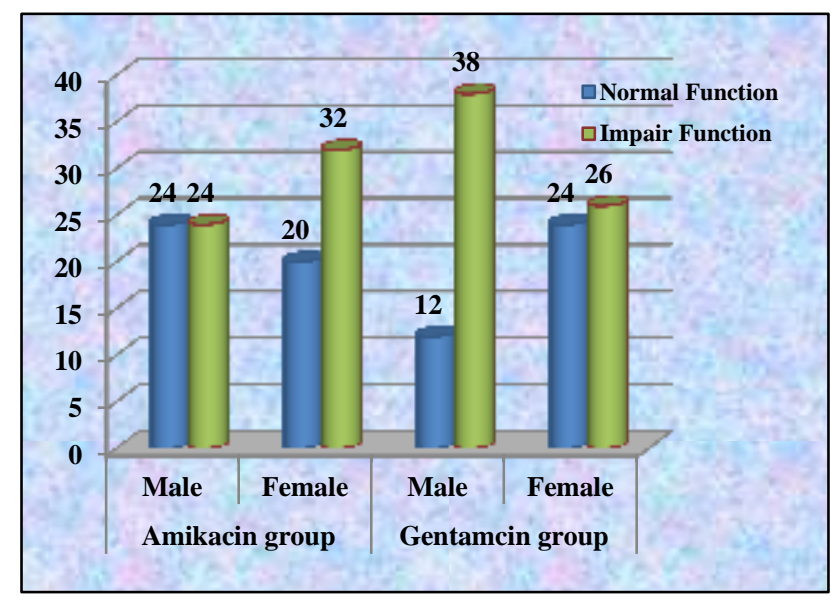

Figure 4: Renal status before surgery.

Renal status showed $44 \%(\mathrm{n}=22)$ with Normal renal function $(24 \%$ male and $20 \%$ female), $56 \%(\mathrm{n}=28)$ with impaired renal function ( $24 \%$ male and $32 \%$ female) in AM group. In case of GM group renal status showed $36 \%$ $(\mathrm{n}=18)$ with Normal function (12\% male and $24 \%$ female) and $64 \%(n=32)$ with impaired renal function (38\% male and 26\% female) (Table 2 and Figure 4).

\section{Variables after undergoing surgery}

The final serum creatinine value after undergoing surgery observed after minimum 6 days were $1.19 \mathrm{mg} / \mathrm{dL}$ and $1.38 \mathrm{mg} / \mathrm{dL}$ with a standard deviation of 0.302 and 0.524 in Amikacin and Gentamicin group respectively. Considering gender, the mean S.Cr was $1.10 \mathrm{mg} / \mathrm{dl}$ and $1.29 \mathrm{mg} / \mathrm{dl}$ in female and male respectively in AM group and in GM group the mean S.Cr values were $1.24 \mathrm{mg} / \mathrm{dl}$ and $1.57 \mathrm{mg} / \mathrm{dl}$ in female and male respectively. The difference in final S.Cr values of both groups were slightly significant (p-value 0.046) (Table 2 and Figure 5).

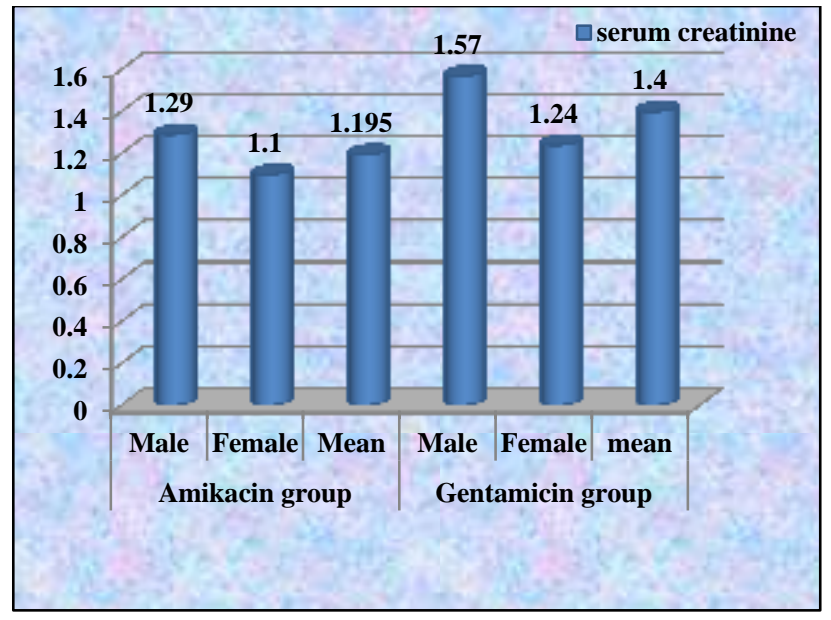

Figure 5: Serum creatinine after surgery.

The mean calculated creatinine clearance value by Cockcroft and Gault method were $57.92 \mathrm{~mL} / \mathrm{min}$ and $52.21 \mathrm{~mL} / \mathrm{min}$ with S.D of 23.78 and 25.18 in AM and GM group respectively. Considering the gender, $\mathrm{Cr}$.Cl is $56.69 \mathrm{~mL} / \mathrm{min}$ for female and $59.26 \mathrm{~mL} / \mathrm{min}$ for male in AM group and in $\mathrm{GM}$ group $52.61 \mathrm{~mL} / \mathrm{min}$ and 51.81 $\mathrm{mL} / \mathrm{min}$ in female and male respectively. The difference in $\mathrm{Cr} . \mathrm{Cl}$ values among two groups is statistically insignificant (Table 2 and Figure 6).

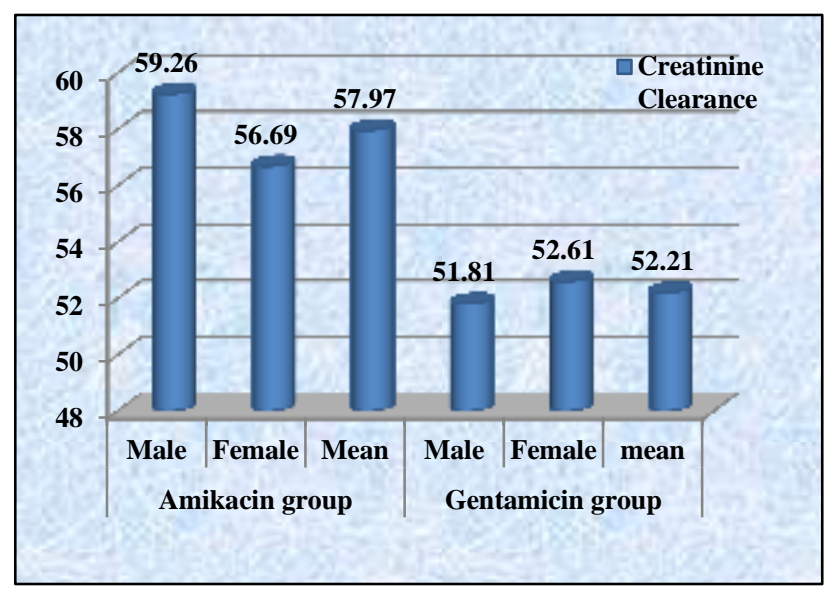

Figure 6: Creatinine clearance after surgery.

Table 3: Guideline to reduce the dose.

\begin{tabular}{|ll|}
\hline Cr.Cl (patient) & Dose rate to be reduced \\
\hline $50-70 \mathrm{ml} / \mathrm{min}$ & $70 \%$ \\
\hline $30-50 \mathrm{ml} / \mathrm{min}$ & $50 \%$ \\
\hline $10-30 \mathrm{ml} / \mathrm{min}$ & $30 \%$ \\
\hline $5-10 \mathrm{ml} / \mathrm{min}$ & $20 \%$ \\
\hline
\end{tabular}

Renal status showed $16 \%$ with normal renal function $(6 \%$ male and $100 \%$ female), $68 \%$ with impaired renal function (36\% male and $32 \%$ female) and $16 \%$ with renal failure (6\% male and $10 \%$ female) in AM group. In case of GM group renal status showed $4 \%$ with normal function ( $2 \%$ male and $4 \%$ female), $72 \%$ with impaired 
renal function (34\% male and $38 \%$ female) and $24 \%$ with renal failure (14\% male and $10 \%$ female) (Table 2 and Figure 7).

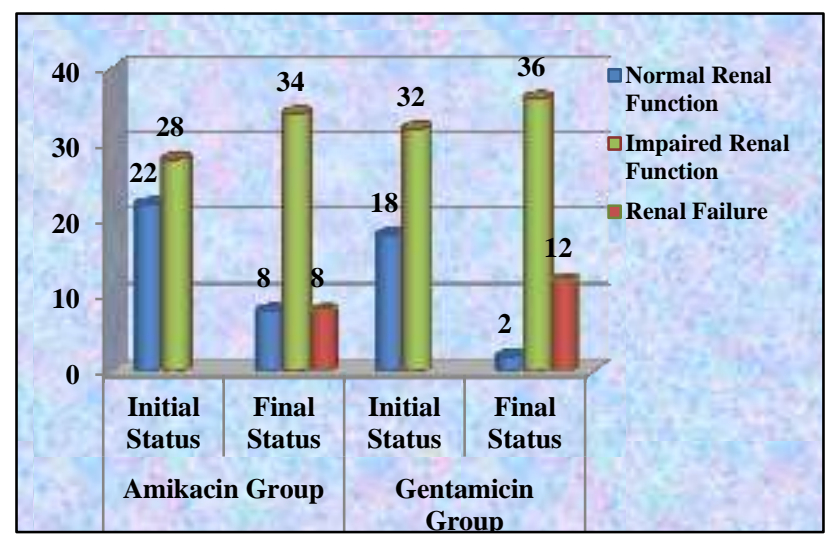

Figure 7: Renal status after surgery.

\section{Difference in final and initial variable}

The mean difference in final and initial serum creatinine values were observed to be 0.32 and 0.52 with a standard deviation of 0.228 and 0.387 in AM and GM group respectively. This difference was statistically significant with $p$ value of 0.007 . The mean difference in final and initial creatinine clearance values were observed to be 18.82 and 24.76 with a standard deviation of 10.14 and 11.93 in AM and GM group respectively. This difference was also statistically significant with p-value of 0.013 (Table 2 and Figure 8 and 9).

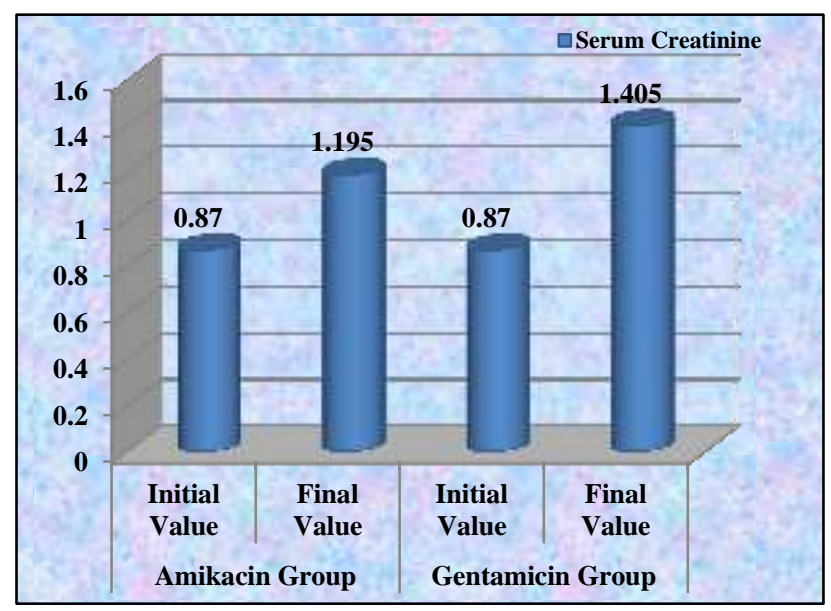

Figure 8: Change in serum creatinine values.

\section{Nephrotoxicity}

Nephrotoxicity occurred in 9 out of 50 patients (18\%) in AM group out of which $12 \%$ were male and $6 \%$ were female whereas in case of GM group nephrotoxicity occurred in 16 out of 50 patients $(32 \%)$ in which $26 \%$ were male and $6 \%$ were female (Table 2 ).

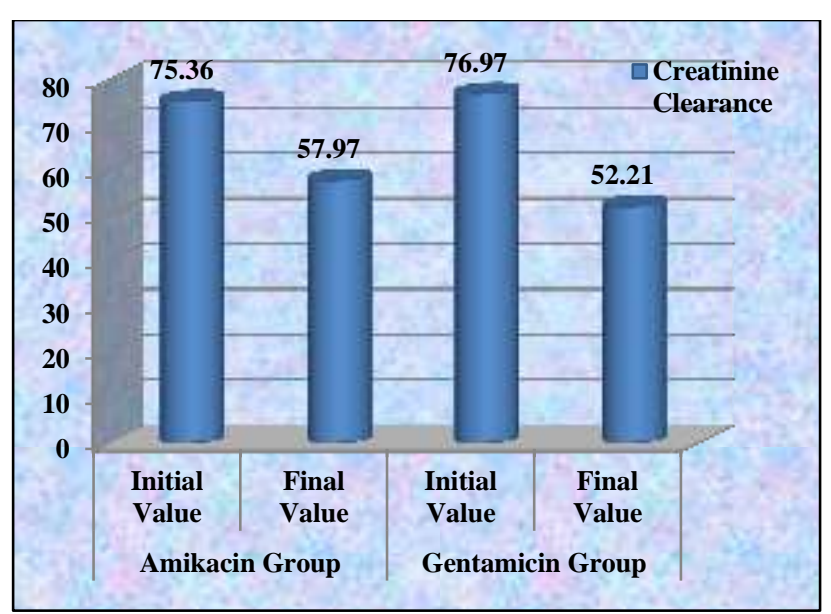

Figure 9: Change in creatinine clearance values.

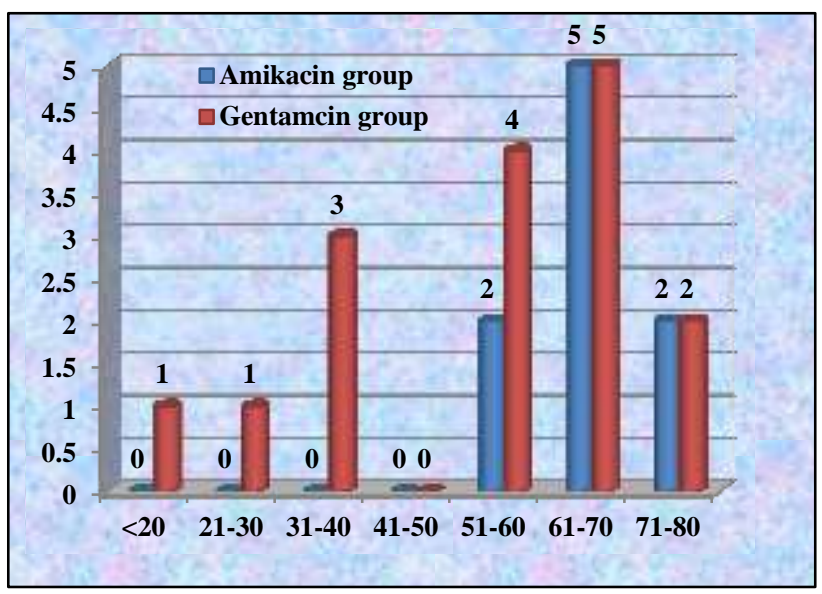

Figure 10: Nephrotoxicity in relation to gender.

In $\mathrm{AM}$ group the number of nephrotoxicity was highest in age group of 61-70 year with $n=5$, followed by age group 51-60 and 70-80 with equal number with $\mathrm{n}=2$. No nephrotoxicity were revealed up to the age of 50 year. In GM Group the nephrotoxicity were observed to be present in all age group except 41-50 year age, the highest occurring in 61-70 year age with $n=5$, followed by 51-60 year age with $n=4$, followed by 31-40 year age with $n=$ 3 , followed by 71-80 year followed by age group 21-30 and below 20 with $n=1$ (Figure 10).

\section{DISCUSSION}

For the treatment of gram - negative infections, in everyday clinical practice, aminoglycosides are most frequently used, although they have nephrotoxic activity characterized by tubular necrosis with gross morphological chances in glomerular structures. ${ }^{8}$ Gentamicin (GM) and Amikacin (AM) are the most frequently used aminoglycosides. The comparative nephrotoxicity of GM and AM in treated human patients is not fully unequivocal.

Comparatively patients of GM group received less dose than that of AM group patients (mean $=2.5 \mathrm{mg} / \mathrm{kg} / \mathrm{day}$ 
and $14.4 \mathrm{mg} / \mathrm{kg} /$ day, respectively). This difference was highly significant $(\mathrm{p}$-value $=0.00)$ but the duration of treatment was similar with mean days of 7.6 and 7.71 (pvalue $=0.61)$. The initial baseline mean serum creatinine clearance was $75.36 \mathrm{ml} / \mathrm{min}$ and $76.97 \mathrm{ml} / \mathrm{min}$ in $\mathrm{AM}$ and GM group respectively $(\mathrm{p}$-value $=0.971)$. No significant difference in initial serum creatinine level noted with value of $0.87 \mathrm{mg} / \mathrm{dL}$ in both groups ( $\mathrm{p}$-value $=0.964$ ). The initial renal status in both group were also not significant $(\mathrm{p}$-value $=0.420)$.

After a week with twice daily infusion of both the group of drugs, there was a significant rise in value of serum creatinine level. The mean final S.Cr level in AM and GM group were $1.19 \mathrm{mg}$ and $1.4 \mathrm{mg}$ respectively (p-value = 0.046). The mean final S.Cr levels were observed to be increased slightly more in males in compared to female. This value is contributed due to higher muscle mass in male.

There was fall in value of creatinine clearance levels after surgery. This fall is indicative of decrease glomerular filtration rate. The mean final clearance values in $\mathrm{AM}$ and GM groups were $57.97 \mathrm{ml} / \mathrm{min}$ and $52.21 \mathrm{ml} / \mathrm{min}$ respectively. GM caused slightly greater fall of $\mathrm{Cr}$. Cl than AM but this was not statistically significant. The renal status of the patients in Gm group were shifted more towards impairment and renal failure from the normal base line function compared to AM treated patient but these shift could not be concluded significant. The mean difference in final and initial serum creatinine values were observed to be 0.32 and 0.52 with a standard deviation of 0.228 and 0.387 in AM and GM group respectively. This difference was statistically significant with $\mathrm{p}$ value of 0.007. The mean difference in final and initial creatinine clearance values were observed to be 18.82 and 24.76 with a standard deviation of 10.14 and 11.93 in AM and GM group respectively. This difference was also statistically significant with p-value of 0.013 . This difference attributes greater degree of fall in creatinine clearance and having a higher potential to cause nephrotoxicity of Gentamicin than Amikacin.

Nephrotoxicity was detected in 25 of the 100 patients (25\%) undergoing surgery in TMU hospital infused with either AM or GM, out of which $9(18 \%)$ out of 50 in AM group and $16(32 \%)$ out of 50 in GM group was observed. These results were similar to prospective comparative study carried out by Ballesteros $\mathrm{J}$ et al who concluded that in patients with normal renal function, GM was significantly more nephrotoxic than AM. ${ }^{9}$ More similar results were observed in study carried out by Waleed $\mathrm{M}$ et al where 16 of 45 patients receiving GM (35.6\%) and 8 of 49 receiving AM $(16.3 \%)$ developed nephrotoxicity. ${ }^{10}$ The results of histopathological comparison conducted by Hadjipour $\mathrm{N}$ et al in 48 rabbits injected with AM and GM demonstrated remarkable and significant difference between two groups. The Amikacin induced necrosis was dramatically less than Gentamicin induced necrosis. ${ }^{11}$ Another prospective, randomized and comparative approach to study the early effects of Gentamicin, Tobramycin, and Amikacin on human kidney showed that AM induced significantly lower lysosomal overloading and no loss of phospholipase A1 activity whereas early lysosomal phospholipidosis produced by GM and Tobramycin cannot be distinguished. ${ }^{12}$ A research carried out to study tissue accumulation by Bonadio $\mathrm{M}$ et al of Dactimicin, Amikacin and Gentamicin showed that Dactimicin as well as Amikacin did not induce any significant increase in BUN and serum creatinine, while Gentamicin administration resulted in severe uraemia in all rats. Consequently a much higher accumulation of Gentamicin than Amikacin and Dactimicin was achieved in serum and tissues. ${ }^{13}$ Another animal experiment carried out by et al in rat model to compare nephrotoxicity of GM and Tobramycin used at similar doses (4 mg/kg/day), predictably produced more renal failure, increased serum creatinine, blood urea nitrogen and morphological evidence of proximal tubular necrosis over 14 days of treatment by GM in compared to Tobramycin. ${ }^{14}$

Study conducted by French MA et al for study of accumulation pharmacokinetics and nephrotoxicity in critically ill patients found no significant differences between their nephrotoxic potential Gatelli JM et al also concluded that nephrotoxicity and auditory toxicity of Amikacin and Tobramicin are not significantly different and that such toxicities are indeed infrequent events. ${ }^{15,16}$ The difference in our results with those obtained by others could be attributed to the differences in the baseline clinical characteristics between the studied groups or differences in the methodology applied, particularly the definition of nephrotoxicity.

In our study, out of 25 nephrotoxicities variation in gender were observed with 19 in males and 6 in females. No gender differences were observed in Amikacin induced nephrotoxicity (12\% in males versus $6 \%$ in females, $\mathrm{P}=0.19$ ). Male and female patients on AM were also comparable in demographic and clinical characteristics. However, significant differences in gender susceptibility were observed with GM induced nephrotoxicity $(26 \%$ in males versus $6 \%$ in males, $\mathrm{P}=$ $0.03)$. These result obviate from study of Waleed $\mathrm{M}$. Concluding no gender differences observed in Gentamicin induced nephrotoxicity (37\% in males versus $33.3 \%$ in females, $\mathrm{P}=0.8$ ). However, significant differences in gender susceptibility were observed with AM induced nephrotoxicity $(31.6 \%$ in females versus $6.7 \%$ in males, $\mathrm{P}$ $=0.043)$. The impact of gender on $\mathrm{AG}$ induced nephrotoxicity is still controversial. Pattern of serum creatinine changes in patients on AM as well as GM were also significant between males and females ( $\mathrm{p}$-values 0.023 and 0.001 respectively). While the pattern of fall in level of creatinine clearance were not significant among gender in AM group (p-value $=0.7)$ and GM group $(\mathrm{p}$ value $=0.9$ ).

In our study the incidence of nephrotoxicity begins from age above 50 year of age with maximum at the age of 61- 
70 in both groups. Only 5 out of 16 nephrotoxicity occurring in GM is below 50 year with absolute no incidence in AM group. This results support the facts that old age being risk factor for nephrotoxicity. For AGs that are eliminated by renal route, kidney function is the key parameter that should be taken into account when dosage regimens are calculated because there is a progressive decline in renal function with aging; the GFR should be estimated for each patient. In cases of declined $\mathrm{Cr}$. Cl, the maintenance doses should be reduced or dose interval prolonged proportionately. A guideline to reduce the dose in given in Table $3 .^{17}$

\section{CONCLUSION}

From this study we can conclude that Gentamicin is more nephrotoxic and causes greater fall in creatinine clearance although the dose of Gentamicin administered is much lower compared to Amikacin. Further, the nephrotoxicity is accentuated by increasing age factor in both groups but variation in gender was seen among them. Gentamicin causes significantly higher degree of nephrotoxicity in male compared to female.

The renal status of the patients in Gentamicin group were shifted more towards impairment and renal failure from the normal base line function compared to Amikacin treated patient but these shift could not be concluded significant.

Funding: No funding sources Conflict of interest: None declared

Ethical approval: The study was approved by the Institutional Ethics Committee

\section{REFERENCES}

1. Stone HH, Kolb LD, Geheber CE, Currie CA. Treatment of surgical infections with Tobramycin. Am Surg. 1975;41:301.

2. Nagai J, Takano M. Molecular aspects of renal handling of aminoglycosides and strategies for preventing the nephrotoxicity. Drug Metab Pharmacokineti. 2004;19:159-70.

3. Lauren G, Kishore BK, Tulkens PM. Aminoglycoside-induced renal phospholipidosis and nephrotoxicity. Biochem. Pharmacol. 1990;40:238392.

4. Leehey DJ, Braun BI, Tholl DA, Chung LS, Gross CA, Roback JA, et al. Can pharmacokinetic dosing decrease nephrotoxicity associated with aminoglycoside therapy. J Am Soc Nephrol. 1993;4:81-90.
5. Gilbert DN. Aminoglycosides. In: Mandell GL, Bennett JE, Dolin R, eds. Principles and practice of infectious diseases. $4^{\text {th }}$ ed. New York: Churchill Livingstone; 1995:279-306.

6. Lott RS, Hayton WL. Estimation of creatinine clearance from serum creatinine concentration. Drug Intell Clin Pharm. 1978;12:140-50.

7. Cockcroft DW, Gault MH. Prediction of creatinine clearance from serum creatinine. Nephron. 1976;16(1):31-41.

8. Martínez-Salgado C, López-Hernández FJ, LópezNovoa JM. Glomerular nephrotoxicity of aminoglycosides. Toxicol Appl Pharmacol. 2007;223(1):86-98.

9. Ballesteros J, Northland R, Wolff M. Gentamicin and Amikacin nephrotoxicity: comparative study in patients with initially normal renal function. Rev Med Chil. 1989;117(1):10-7.

10. Sweileh WM. A prospective comparative study of gentamicin and Amikacin induced nephrotoxicity in patients with normal baseline renal function. Fundam Clin Pharmacol. 2009;23(4):515-20.

11. Hadjipour N. Histopathological comparision of Gentamicin and Amikacin nephrotoxicity in rabbits. Journal of Animal and Veterinary Advances. 2011;10(8):1003-6.

12. De Broe ME, Paulus GJ, Verpooten GA, Roels F, Buyssens N, Wedeen R, et al. Early effects of Gentamicin, Tobramycin, and Amikacin on the human kidney. Kidney International. 1984;25:64352.

13. Bonadio M, Maccanti O, Giovannini L, Bertelli AA, Scalori V, Alessandrì MG, et al. Comparative nephrotoxicity and tissue accumulation of dactimicin, Amikacin and Gentamicin. Drugs Exp Clin Res. 1987;13(12):747-50.

14. Gilbert DN, Plamp C, Starr P, Bennett WM, Houghton DC, Porter AG. Comparative nephrotoxicity of Gentamicin and Tobramycinin Rats. Antimicrobial agents and chemotherapy, 1978;34-40.

15. French MA, Cerra FB, Plaut ME, Schentag JJ. Amikacin and gentamicin accumulation pharmacokinetics and nephrotoxicity in critically ill patients. Antimicrob Agents Chemother. 1981;19(1):147-52.

16. Gatell JM, San Miguel JG. Zamora L. Araujo V, Bonet M, Boht M, et al. Marin'. Comparison of the nephrotoxicity and auditory toxicity of tobramycin and Amikacin. Antimicrobial Agents And Chemotherapy. 1983;23(6):897-901.

17. Tripati KD. Essentials of medical pharmacology, $7^{\text {th }}$ Edition. 2013;68.

Cite this article as: Bajracharya S, Pandey K, Haque A. To evaluate the creatinine clearance and compare nephrotoxic potential of amikacin and gentamicin, in post-operative patients with normal baseline renal function. Int J Basic Clin Pharmacol 2016;5:1942-8. 